\title{
Propuesta de herramientas de información estadística para la Fundación Angelitos Por Siempre
}

\author{
Bra. María Alejandra Ramos, Bra. Judith Amara Buitrago. \\ POLISAL, UNAN- Managua. ${ }^{1}$ \\ Recibido 24 de abril 2013- Aprobado 28 de octubre 2013.
}

\section{RESUMEN}

El proyecto de creación de herramientas sobre recopilación de información estadística en la rehabilitación de niños con discapacidad se desarrolló durante once semanas de las prácticas de especialización I, por estudiantes de Fisioterapia en la Fundación Angelitos Por Siempre del municipio de Masatepe. El objetivo del proyecto fue diseñar un sistema de formatos básicos que permitiera obtener y brindar información comprensible y útil para el desarrollo de actividades administrativas y de gestión financiera. Es importante registrar la información de sobre la atención brindada a los pacientes que asisten al centro porque permitirá visualizar la información para ser utilizada en la planificación de acciones para beneficio de la población con discapacidad. El avance de este proyecto se desarrolló en dos etapas: la identificación de las necesidades y la planificación de tareas operativos para la creación de instrumentos de recopilación de información. El resultado obtenido fueron herramientas diseñadas de fácil manejo para el personal así como también de importancia para tener un registro de todas las personas con discapacidad que atiende el centro como una institución prestadora de servicios a los niños con discapacidad del municipio de Masatepe.

Palabras clave: discapacidad, ereación, herramientas de recopilación de información.

\section{INTRODUCCIÓN}

Este proyecto se formuló a partir de las necesidades identificadas por un grupo de estudiantes de II año de Fisioterapia durante las Prácticas de Especialización I del plan de estudio que posteriormente se convierte en un plan operativo práctico para la ejecución de la creación de herramientas de recopilación de información estadística en la rehabilitación de niños con discapacidad.

En el municipio de Masatepe se localiza el Centro de Rehabilitación Angelitos por siempre que brinda atención en las especialidades de Fisioterapia, Psicología y Pedagogía a niños con discapacidades motoras, auditivas, cognitivas y de lenguaje. Uno de los problemas identificado en la gestión administrativa que realiza la junta directiva de padres de familia fue la falta de un sistema de registro de información sobre los niños que asisten al centro. Esto repercutía negativamente, porque no se perdía la oportunidad de la realización de proyectos auspiciados por organismos gubernamentales y no gubernamentales.

La metodología utilizada para la elaboración de este proyecto fue participativa ya que se realizaron consensos entre estudiantes, padres de familia y profesionales para el diseño de las herramientas a utilizar. Se determinó que se realizaría en base a datos demográficos tales como edad sexo y servicios que la población demanda, los cuales fueron plasmados en una hoja de registro mensual y una ficha de ingreso piloteadas durante 4 semanas para constatar su efectividad y viabilidad. En base a la problemática observada, se resolvió crear herramientas estadísticas de fácil manejo, pero que permitiera registrar información objetiva para ser utilizada en la elaboración de proyectos que beneficie a la población de niños con discapacidad.

\footnotetext{
${ }^{1}$ Trabajo dirigido por la licenciada Virginia Josefa Conrado Rodríguez
} 


\section{MATERIALES Y MÉTODOS}

La metodología utilizada para el desarrollo de este proyecto contempló dos momentos de los cuales se fundamentan paso a paso en los diferentes procesos siendo estas las siguientes: La identificación de problema y planificación. Para la identificación del problema se analizaron las necesidades existentes para la búsqueda de estrategias, y de esa manera dar solución al problema seleccionado a continuación se determinó la etapa de planificación a través de planes operativos semanales los cuales se desarrollaron durante un periodo de once semanas comprendidas de marzo a junio. Durante el desarrollo de los planes semanales se concretaron diversas actividades como pilotajes de las herramientas que nos ayudaba a la mejora de los mismos así mismo se fortaleció al personal del centro con un taller de capacitación para el manejo y uso correcto de dichas herramientas.

\section{RESULTADOS}

\section{Identificación de necesidades}

$>$ Inadecuado registro de información.

$>$ Carencia de un registro mensual de asistencia de los usuarios del servicio.

$>$ Inadecuada organización de los expedientes.

$>$ Carencia de una ficha de registro de ingreso.

$>$ Falta de sistematización de la información.

$>$ Desconocimiento sobre el manejo de herramientas de registro información por parte de los integrantes de la directiva.

\section{Propuesta de herramientas}

Imagen 1 Tarjeta de citas

Imagen 2. Cuaderno de citas por especialidad
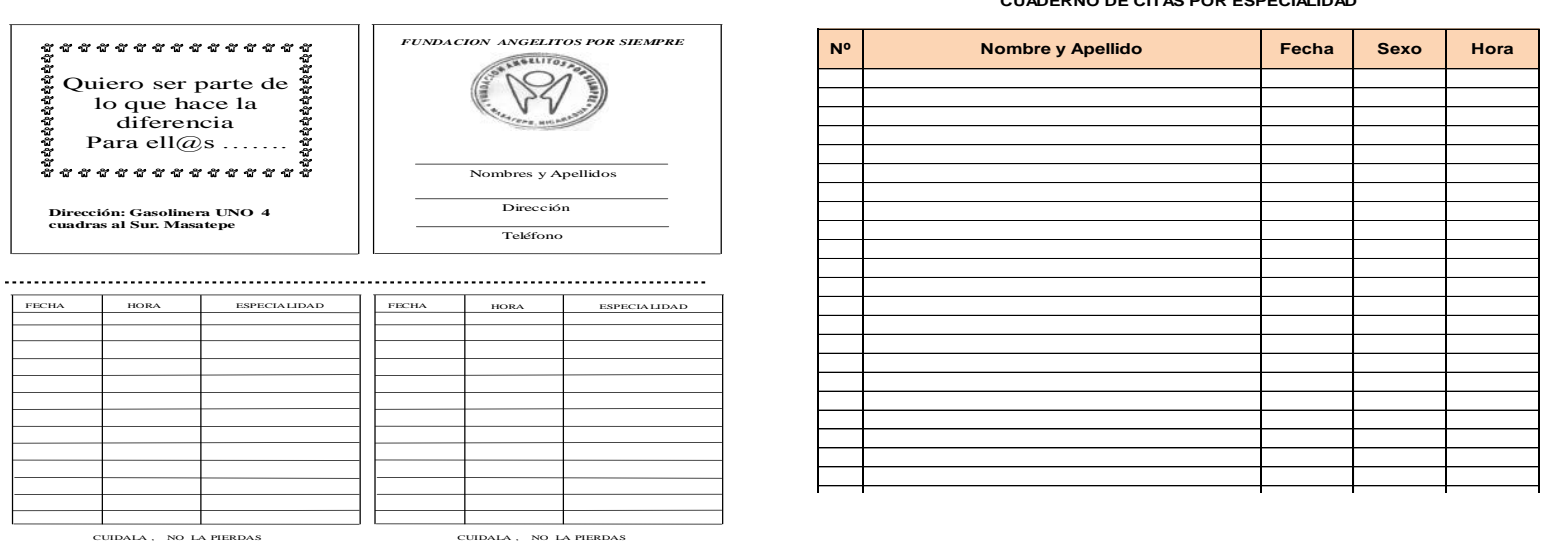

Imagen 3. Hoja de registro mensual

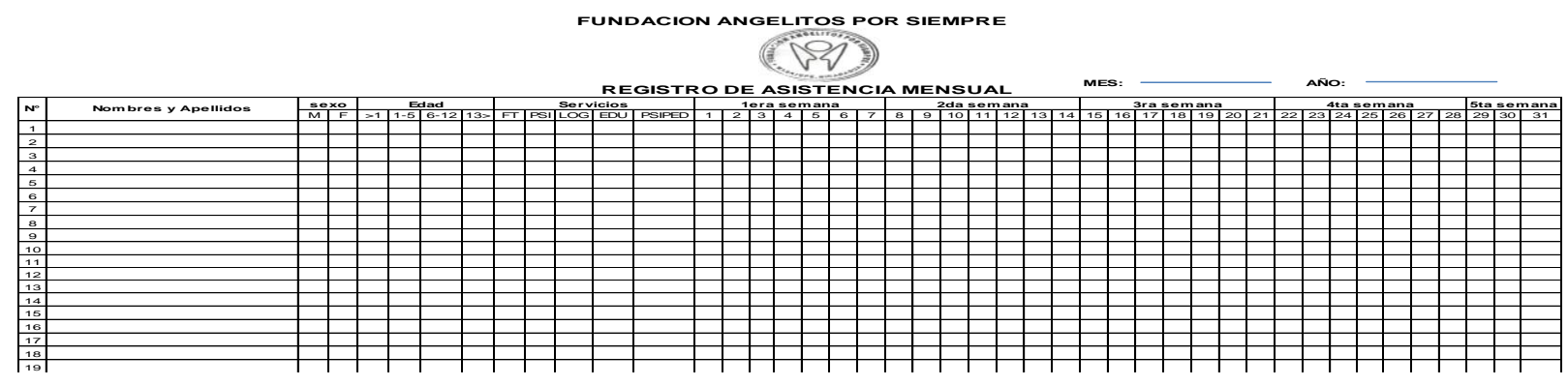


Imagen 4. Ficha de ingreso
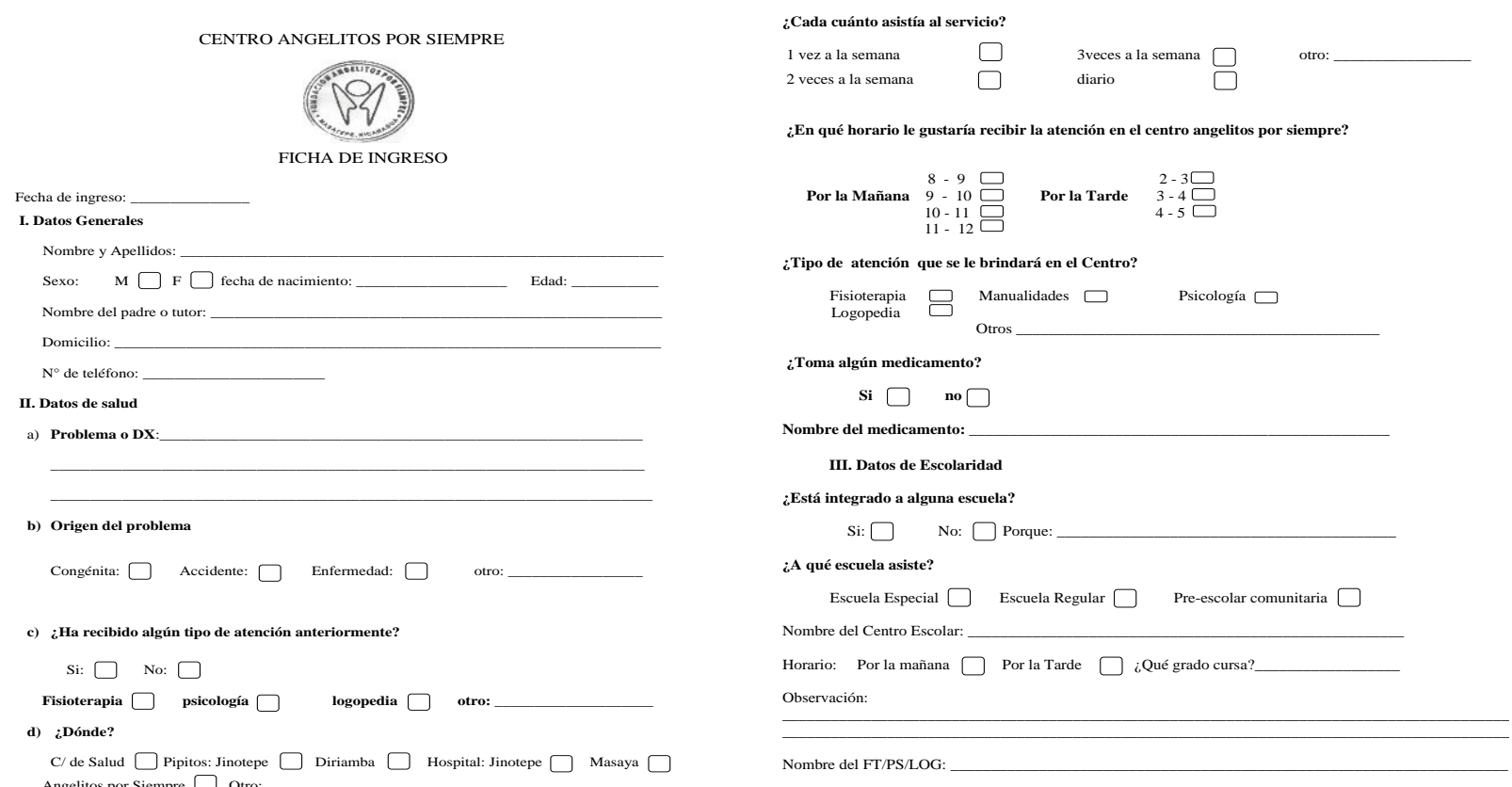

\section{Resultados esperados}

$>$ Elaboración de varios tipos de formatos físicos y digitales para la recopilación de información.

$>$ Capacitación en el manejo adecuado de los instrumentos implementados.

$>$ Utilización adecuada de los diferentes instrumentos de información.

\section{CONCLUSIÓN}

La creación de herramientas de recopilación de información fue un hecho que en general estableció un sistema que permitiera una mejor organización así como también un mayor control sobre datos pertinentes de los niños que demandan servicios especializados en la institución.

\section{AGRADECIMIENTO}

Por nuestra excelencia y formación profesional, gracias a su cariño, guía y apoyo. Este presente simboliza nuestra gratitud por toda la responsabilidad e invaluable ayuda que siempre nos ha proporcionado Lic. Virginia Josefa Conrrado Rodríguez.

\section{BIBLIOGRAFÍA}

Alvarado, E. \& pineda, E.(1997). Metodología de la investigación manual del desarrollo personal de la salud. ( $3^{\mathrm{a}}$.ed.), Editorial LIMUSA.S.A.

Piura, J. (1958).Introducción a la metodología de la investigación científica. (4a .ed). Nicaragua: publicación científica de la escuela de salud pública. 